\title{
Antecedentes do Engajamento e da Intenção em Permanecer em Projetos Sociais: Um Estudo em Instituições de Ensino Superior do Estado de São Paulo
}

\author{
Ana Rosa da Silva, \\ Universidade Metodista de São Paulo - Brasil \\ aninharosa@globo.com \\ Alexandre Cappellozza, \\ Universidade Metodista de São Paulo - Brasil \\ alexandre.cappellozza@metodista.br \\ Felipe Zambaldi \\ Fundação Getulio Vargas - Escola de Administração de Empresas de São Paulo - Brasil \\ felipe.zambaldi@fgv.br
}

\section{Resumo}

Algumas organizações têm se preocupado em oferecer projetos sociais que englobam a comunidade em geral e os seus colaboradores. Esses projetos são realizados com a participação do trabalho voluntário. Analisar os fatores antecedentes que movem o cidadão voluntário a permanecerem nos projetos sociais e a se engajarem nas instituições onde são prestados esses trabalhos sociais é a proposta deste estudo. A pesquisa fundamenta-se em uma abordagem de investigação quantitativa e o estudo foi exploratório com corte transversal único, onde os dados foram coletados por meio de um instrumento de pesquisa com a obtenção de 351 questionários respondidos. Para os testes das hipóteses do estudo, foi realizada a análise de equações estruturais, com base no PLS-PM (Partial Least Squares Path Modeling), onde foram apresentadas medidas satisfatórias para os construtos investigados e o modelo proposto, sendo significantes algumas relações entre os construtos. Os resultados indicam que os custos de troca e o altruísmo influenciam positivamente no engajamento dos indivíduos na organização que desenvolve projetos sociais e que o engajamento e custos de troca também impactam positivamente na intenção de permanecer nos projetos sociais. A compreensão de motivações e determinantes do comprometimento com o trabalho 
voluntário torna-se crucial para que os gestores desta força de trabalho possam desenhar mecanismos eficazes de atração, engajamento e retenção.

Palavras-chave: altruísmo, engajamento, custos de troca, projetos sociais. 


\title{
Antecedents of Engagement and Intention to Work in Social Projects: A Study in Higher Education Institutions in Sao Paulo
}

\author{
Ana Rosa da Silva, \\ Universidade Metodista de São Paulo - Brasil \\ aninharosa@globo.com \\ Alexandre Cappellozza, \\ Universidade Metodista de São Paulo - Brasil \\ alexandre.cappellozza@metodista.br \\ Felipe Zambaldi \\ Fundação Getulio Vargas - Escola de Administração de Empresas de São Paulo - Brasil \\ felipe.zambaldi@fgv.br
}

\begin{abstract}
Some organizations have been concerned in offering social projects that involve its employees. This study proposes to identify individual factors that promotes to work in social projects in educational organizations. The research is based on a quantitative research approach with single cross-section exploratory study, where data were collected through a survey, obtaining 351 completed questionnaires. To test the study hypothesis, structural equations based on PLS-PM (Partial Least Squares Path Modeling) were analyzed. The results indicate that switching costs and altruism positively influence the engagement of individuals to work for social projects. Besides these results, engagement and switching costs positively influence the intention to keep employees working in social projects. Understanding motivations and determinants of voluntary work is crucial for managers to design effective mechanisms of attraction, engagement and retention of volunteers.
\end{abstract}

Keywords: altruism, commitment, switching costs, social projects. 
O setor privado vive pressionado pelos conceitos do capitalismo que impulsionam as empresas em busca de resultados financeiros. Uma das responsabilidades de uma empresa é a maximização do seu desempenho econômico e suas responsabilidades sociais são, geralmente, limitadas ao cumprimento da legislação (Friedman, Manly, McMahon, Kerr, \& Stark, 1984).

Faz parte do papel de algumas empresas o envolvimento com questões sociais, isso significa que empresas devem assumir uma postura ativa frente aos problemas que emergem em seu entorno social (Drucker, 1997). Mas, ao explorar os benefícios da filantropia e do envolvimento social, pode-se alinhar ganhos sociais e ganhos econômicos, a partir da avaliação do potencial estratégico das ações sociais que a empresa realiza.

O foco apenas na maximização do lucro das empresas não se mostra mais como a única estratégia utilizada pelas organizações (Porter \& Kramer, 2002). Participar de projetos sociais significa, muitas vezes, trabalhar de forma voluntária em Organizações nãogovernamentais, e o comprometimento com essa atividade exige que o indivíduo tenha preditores motivacionais ou incentivos para mantê-lo atuante nesse trabalho (Smith, 1982).

Investindo em projetos sociais, a instituição assume a sua responsabilidade social e oferece algo em troca. Por exemplo, alguns alunos recorrem ao Fundo de Financiamento Estudantil - FIES, que é um programa do Ministério da Educação destinado a financiar a graduação na educação superior de estudantes matriculados em cursos superiores. Um grupo de Instituições educacionais de curso superior criaram um projeto alinhado com organizações não governamentais para a amortização desse financiamento. A inserção dos alunos do curso superior no programa possui alguns critérios e um deles é a responsabilidade da contrapartida social, que são atividades voluntárias, realizadas pelos alunos inseridos no programa, em projetos específicos, realizadas em Organizações não Governamentais. Finalizado o período contratual e cumpridas todas as exigências, o saldo final do financiamento FIES, será amortizado pela instituição e não pelo contratante do empréstimo (Pedagógico, 2015).

Apesar dos benefícios de amortização do financiamento FIES, oferecido pelo programa, uma parcela dos contratantes do Fundo de Financiamento Estudantil que aderiram aos projetos sociais, acabam por desistir de participar do trabalho voluntário. Além disso, as pessoas participam de programas sociais por motivos que não são claramente 
identificáveis (Mascarenhas et al., 2013). O desenvolvimento de estudos que possam ampliar a compreensão do engajamento, valores humanos (Coelho, 2014) e aspectos econômicos individuais na participação de projetos sociais é um tema pouco explorado. Assim este estudo tem por objetivo identificar elementos, no processo decisório, que contribuem para a permanência dos participantes voluntários nesses projetos.

Diante deste contexto, de forma a direcionar o estudo, é apresentada a seguinte questão de pesquisa: qual a influência do Altruísmo e dos Custos de Troca no Engajamento e na Intenção de Permanecer em Projetos Sociais?

\section{Referencial teórico}

\section{Trabalho voluntário}

O trabalho voluntário representa uma das bases de sustentabilidade das Organizações Não-Governamentais - ONGs, principalmente para a manutenção e continuidade dos projetos institucionais. O trabalho voluntário tem sido valorizado por empresas privadas, assistenciais, igrejas e governo. Muitos desses projetos representam iniciativas dos participantes das instituições (Domeneghetti, 2001).

O voluntariado é definido, pelas leis brasileiras, de acordo com a lei 9.6o8/98, como o "cidadão que, motivado pelos valores de participação e solidariedade, doa seu tempo, trabalho e talento, de maneira espontânea e não remunerada, para causas de interesse social e comunitário".

Existem duas razões para uma pessoa dedicar-se voluntariamente a algum tipo de atividade. A primeira razão é representada pelo ato de fazer o bem através da ajuda aos necessitados, o que pode caracterizar um impulso altruísta. A segunda razão se destaca pelo interesse do voluntário que busca desenvolver capacidades profissionais, com a vivência de experiência proporcionada pela execução do trabalho, ou seja, o voluntário utiliza sua experiência para contribuir com a sociedade. Um outro elemento que está ligado ao trabalho voluntário é a noção de caridade, que também é incentivada por diversas religiões. Entretanto, surgem novas organizações voluntárias que não estão ligadas a nenhuma 
religião e que, além da ideia de caridade, são reforçadas pela ideia de cidadania (Coelho, 2014).

Explicar e prever o comportamento dos indivíduos, sempre foi um dos focos de pesquisa na área do comportamento do consumidor e da psicologia social. Consequentemente, diversas teorias foram criadas e vêm sendo estudadas, testadas e comparadas entre si nos últimos anos, cuja intenção primordial é desenvolver cada vez mais o entendimento sobre o comportamento humano (Moura, Veiga, Cunha \& Moura, 2010).

As atitudes podem ser utilizadas para explicar comportamentos sociais, isto é, conhecendo-se as atitudes de uma pessoa em relação a um determinado objeto, é possível fazer inferências sobre seu comportamento (Thomas \& Znaniecki, 1918).

Por outro, há uma defesa de uma organização tridimensional das atitudes (Rosenberg \& Hovland, 1960), onde encontra-se definições das atitudes como predisposições para responder a uma classe de estímulos com certas classes de resposta designadas como cognitiva, afetiva e comportamental (Rosenberg \& Hovland, 1960), caracterizando a conceituação de altruísmo.

\section{Altruísmo}

Altruísmo é uma palavra percebida muitas vezes como sinônimo de solidariedade. A palavra altruísmo representa um conceito estabelecido em 1830 pelo filósofo francês Augusto Comte para caracterizar o conjunto das disposições humanas (individuais e coletivas) que inclinam os seres humanos a dedicarem-se aos outros (Comte, 1934). Esse conceito opõe-se, portanto, ao egoísmo que são as inclinações específicas e exclusivamente individuais, sejam pessoais ou coletivas (Japiassú, 1990).

Este conceito de altruísmo também se faz presente no manifesto do altruísmo criado por Lacerda (2015). Nesse manifesto se proclama a necessidade de vincular-se o direito de liberdade individual ao dever de cada um de empenhar-se pelos semelhantes (Lacerda, 2015). O altruísmo era uma forma de amor ao mesmo tempo instintiva e pensada, expressa "atos de afeto" ou em "viver para o outro" (Comte, 1934). Como as atitudes altruístas são, por natureza, as únicas desinteressadas, a moralidade poderia se fundamentar nas emoções. 
Seria um tipo de "religião da gentileza", o que pode ser denominado de liberalismo altruísta (Comte, 1934).

Altruísmo não é um processo de troca, pois processos de troca são regidos pela norma moral da reciprocidade, que especifica que um retorno deve ser dado para os benefícios recebidos, porém a norma da reciprocidade não está completamente onipresente, pois há pessoas que são incapazes de retribuir, em especial os muito jovens e os idosos muito doentes (Leeds, 1963). O altruísmo apresenta características principais: (a) apresenta um fim em si mesmo e não é direcionado a um ganho ou lucro, (b) é voluntário e (c) se propõe a fazer o bem (Rivera, 1980).

A busca por uma identificação das variáveis que estão associadas ao altruísmo tem-se mantido ao longo do tempo, existem evidências do papel de moderadores e mediadores como dispositivos de aprendizagem, normas pessoais e sociais, ou fatores como a percepção de responsabilidade, empatia afetiva e cognitiva ou a atração (Penner, 2002; Sturmer, Snyder, \& Omoto, 2005).

Podem ser identificadas três dimensões das atitudes: o componente cognitivo que inclui percepções e conhecimentos sobre o objeto em foco; o componente emocional ou afetivo que representa sentimentos em relação ao objeto; e o componente comportamental que chama a atenção para reações humanas em relação a ele (Loureiro \& Lima, 2009).

Essas dimensões compõem as atitudes altruístas do indivíduo. Indivíduo com atitudes altruístas está orientado para os outros (Donat, Brandtweiner, \& Kerschbaum, 2009).

Dessa forma, participar dos projetos sociais, através dos trabalhos voluntários pode ser motivado por altruísmo e, pessoas altruístas tendem a se engajar no trabalho. Portanto, elaborou-se a primeira hipótese deste estudo:

\section{H1: O Altruísmo influencia positivamente no engajamento das pessoas no} trabalho voluntário.

É possível estabelecer graduações entre diversas formas de ação altruísta. O grau de altruísmo varia na medida que envolve mais ou menos considerações, muitas vezes até egoístas, como o vínculo afetivo que o indivíduo tem com o destinatário da ação, o benefício 
de receber algo como também o benefício em se proclamar altruísta, ou ainda o retorno futuro que o altruísta espera receber por sua ação etc. (Elster, 1989).

Dessa forma, permanecer nos projetos sociais pode ser motivado por altruísmo. Portanto, elaborou-se a segunda hipótese desse estudo:

\section{H2: O Altruísmo influencia positivamente na intenção de permanecer nos} projetos sociais.

Além das atitudes altruístas, outro aspecto pode afetar a intenção de permanecer nos projetos sociais - o engajamento no trabalho que é percebido pelo indivíduo através da demonstração de energia, envolvimento e eficácia (Leiter, 1997).

\section{Engajamento no Trabalho}

O trabalho pode apresentar efeitos positivos e negativos na vida das pessoas, dependendo de como essa relação laboral ocorre. Pode-se observar esses efeitos do trabalho na expressão latina labor y opus: o primeiro termo, labor, se refere ao trabalho relacionandoo como uma atividade que requer o dispêndio de muito esforço e energia, ao passo que o segundo termo, opus, diz respeito a aspectos criativos do trabalho (Salanova, M., Salanova, W., Schaufeli, Salanova, M., Salanova, S., 2009).

Trabalhadores engajados investem mais energia nas suas tarefas, demonstrando entusiasmo e foco na realização das mesmas. O trabalho na vida do indivíduo passa a ser considerado como algo que deva proporcionar felicidade, portanto, diminui o estresse (Bakker \& Demerouti, 2008).

O engajamento no trabalho é um construto resultante de estudos sobre a síndrome de burnout (Maslach, Schaufeli, \& Leiter, 2001), que resultam de estudos da psicologia positiva. Pesquisadores que estudam sobre a síndrome de burnout passaram a dar um enfoque maior aos aspectos positivos do ser humano, como no caso dos estudos relacionando burnout e engajamento no trabalho (Carvalho \& Barbalho, 20o6; Maslach et al., 2001) 
A palavra engajamento tem sua origem etimológica na palavra francesa engagement, no sentido de uma garantia através de um documento ou dinheiro (Houaiss \& Villar, 2009). Academicamente, a primeira pessoa que conceituou engajamento foi Willian A. Kahn, em 1990, no artigo intitulado "Psychological conditions of personal engagement and disengagement at work"(Kahn, 1990).

O envolvimento dos trabalhadores é significativamente influenciado por todos os elementos inseridos no processo de trabalho, como pessoas, por exemplo. As maiores oportunidades de aprendizagem tem efeitos diretos sobre como aumentar o engajamento de trabalho entre os funcionários de serviços de saúde, além disso, o apoio do colega de trabalho, bem como do supervisor também desempenham um papel positivo e significativo para estimular o engajamento trabalho (Sarti, 2014).

O engajamento no trabalho é considerado um estado mental positivo assentado em crenças a respeito da intensidade com que o indivíduo se sente vigoroso e absorvido enquanto realiza suas atividades (Siqueira, Martins, Orengo, \& Souza, 2014 ).

O indivíduo que apresenta vigor e absorção, também costuma apresentar níveis acentuados de otimismo, resiliência, esperança e eficácia e consequentemente envolvimento no trabalho e comprometimento organizacional afetivo, gerando maior engajamento (Cavalcante, Siqueira, \& Kuniyoshi, 2015).

Por se tratar de uma forma de comportamento, o engajamento supõe motivação, fator que faz acontecer o engajamento e lhe dá uma direção. A intensidade e a qualidade do engajamento tem sido associadas às modalidades excelentes de motivação, que são a motivação intrínseca, as formas autodeterminadas da motivação extrínseca, bem como a orientação para o trabalho ou à meta domínio (Harris, 2011; Reeve, Deci, \& Ryan, 2004).

As pessoas engajadas podem estar motivadas extrinsecamente por regulação externa, ou seja, fatores que não estão sob o controle do indivíduo, e a pessoa atende a controladores externos, agindo, por exemplo, em função de alguma recompensa, ou para evitar punições e perdas (Harris, 2011; Reeve et al., 2004).

Pressupõe-se que o engajamento no trabalho pode estar relacionado como um preditor direto do envolvimento das pessoas nas organizações. Pessoas engajadas tendem a executar suas atribuições com mais vigor e dedicação, e consequentemente podem permanecer atuantes nas organizações (Cavalcante et al., 2015). 
Assim, elaborou-se a terceira hipótese deste estudo:

\section{H3: O engajamento das pessoas na organização influencia positivamente na} intenção de permanecer nos projetos sociais.

Estudos indicam que os indivíduos recebem benefícios em troca de sua atuação em trabalhos voluntários (Pearce, 1998; Rose-Ackerman, 1997). Não se trata de dizer que os voluntários estejam desinteressados em ajudar aos outros, mas sim, que este motivo provavelmente não seja tão dominante quanto pareça, muitas vezes, para motivar a participação e o envolvimento no serviço voluntário, ocorre a negociação, um contrato ou acordo e também a barganha ou permuta (Smith, 1982).

A decisão dos voluntários em permanecerem atuantes nos projetos sociais, com a responsabilidade de desenvolver trabalhos de contrapartida social, pode ser motivada por diversas variáveis, como a percepção de custos e sacrifícios que estarão inseridos no processo de mudança, ou seja, em sair dos projetos sociais (Burnham, Frels, \& Mahajan, 2003).

\section{Custos de Troca}

De uma forma geral, os custos de mudança podem ser analisados em termos de gastos econômicos e custos intangíveis, difíceis de serem mensuráveis, pois se referem às relações que são geradas no decorrer da permanência com aquele provedor, fornecedor ou instituição e, a mudança de relacionamento com o fornecedor do produto ou serviço, tornase um elemento que pode caracterizar uma perda ou custo (Grzybowski, 20o8; Gómez \& Maícas, 2011).

A construção de custo de troca, foi conceituada como a percepção da magnitude dos custos adicionais necessários para os indivíduos que desejam terminar o relacionamento atual com sua instituição (Porter, 1992). Os custos de troca têm sido identificados como um fator que contribui para a manutenção de um relacionamento (Morgan \& Hunt, 1994).

A existência de grande concorrência que existe entre as organizações é um dos motivos que as levam a desenvolver esforços de atração e retenção de clientes. $\mathrm{O}$ ambiente acirrado de competição e disputas, as exigências de estratégias que propiciem vantagens 
competitivas geram discussões sobre os custos de troca e benefícios oferecidos e sua eficácia na retenção e manutenção do cliente na instituição (Alves, Terres, \& Santos, 2013).

Os custos de troca podem ser derivados de fontes negativas de confinamento, que é o aprisionamento do cliente junto à organização, por exemplo, o desgaste para encontrar um novo fornecedor, como também existem os custos de troca que derivam de fontes positivas de confinamento, por exemplo, perda de laços pessoais ou de descontos especiais (Jones, Reynolds, Mothersbaugh, \& Beatty 2007).

Assim, os custos de procedimentos, relacionados ao desgaste, são considerados custos negativos de troca, enquanto custos de benefícios perdidos e custos sociais de mudança são exemplos de custos de troca positivos. Para a distinção entre os dois sentidos é preciso saber se os custos de troca derivam, ou não, de benefícios e valores aos quais o consumidor terá de renunciar (Jones et al., 2007).

Os custos de troca podem realmente existir ou apenas ser percebidos pelos indivíduos. Muitas vezes, antes de adquirir um produto ou a inserção em algum programa, os custos de troca podem parecer ser inexistentes, mas depois que a compra é executada, os custos escondidos podem aparecer tanto por imposição das empresas ou indiretamente pela própria natureza do serviço (Klemperer, 1995).

Ao estudar tipos, antecedentes e consequências dos custos de troca, Burnham et al. (2003) falam da "lealdade passiva" gerada pelos custos de troca, que podem ser conceituados como "custos que os clientes associam com o processo de troca de um fornecedor para outro”. É importante destacar que os custos de troca não estão relacionados imediatamente com a troca em si. Eles estão associados ao processo de mudar, significando assim, que não se limitam aos gastos econômicos, mas estão representados por diversos tipos de impedimentos e custos, tais como: custo de busca, de transação, de aprendizagem, de hábitos do cliente, de benefícios adquiridos, de relacionamentos estabelecidos, de custo emocional, de esforço cognitivo, de risco financeiro, social e psicológico por parte do comprador. Tais custos não estão expressos de forma mensurável, mas são percebidos pelo cliente, quando este se depara com o processo de troca (Burnham et al., 2003).

O custo de troca no âmbito financeiro envolve a perda de recursos financeiros quantificáveis dentre esses a perda de benefícios e a perda monetária. Os custos de troca podem criar um relacionamento atraente tanto para o cliente como para empresa. Ou seja, 
uma relação de ganha-ganha. Um exemplo seriam os custos de perda de benefícios, ou perdas de vantagens financeiras existentes em permanecer com o fornecedor atual, tais como pontos em programas de fidelidade, amortização financeira, como ocorre com as instituições analisadas neste estudo. Ambas as partes são beneficiados pelo custo de troca. $\mathrm{O}$ cliente, através do direito aos benefícios, e a empresa, ao ter um cliente (Burnham et al., 2003).

Os benefícios adquiridos por atuar no trabalho voluntário pode ser um motivador para o engajamento dos indivíduos no trabalho voluntário (Bakker \& Demerouti, 2010). Desta forma, elabora-se a quarta hipótese deste estudo:

\section{H4: Os Custos de troca influenciam positivamente no engajamento dos alunos} nos projetos sociais.

Os custos de troca, como a perda de benefícios são positivamente associados ao comprometimento afetivo, o indivíduo se identifica com a organização e com os objetivos dela e deseja manter-se como membro, de modo a facilitar a consecução desses objetivos. Por outro lado, os custos processuais se relacionam com o comprometimento calculativo, que se refere ao comprometimento como função das recompensas e dos custos pessoais. Tal ação baseia-se no fato de que tanto a perda de benefícios quanto as mudanças sociais refletem valores e comportamentos positivos que podem ser sacrificados no processo de mudança (Jones et al., 2007). Nesse sentido, foi possível medir o impacto dos custos de mudança na intenção comportamental de permanecer junto à organização.

Estabelecer uma nova relação com outra instituição pode representar investimento de esforço, tempo e dinheiro, além da perda de benefícios já adquiridos com a empresa atual, o que podem fazer com que o cliente permaneça com a empresa do momento (Lam, Shankar, Erramilli, \& Murthy, 2004). Portanto, elabora-se a quinta hipótese deste estudo:

H5: Os Custos de troca influenciam positivamente na intenção de permanecer nos projetos sociais. 
Com base nos estudos que levaram à criação das diversas hipóteses deste estudo, elabora-se um modelo conceitual a ser explorado nesta pesquisa, apresentado na figura 1.

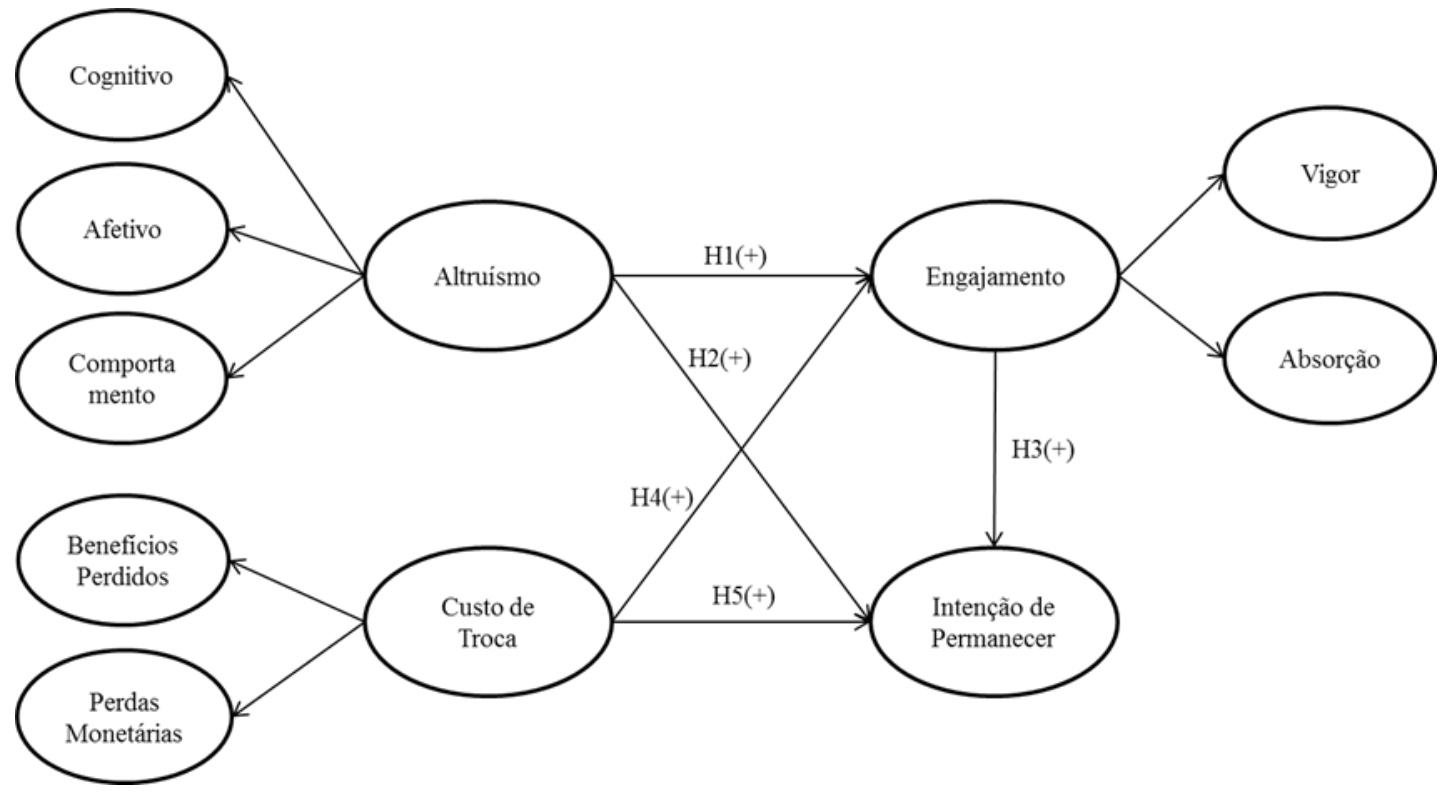

Figura 1. Modelo conceitual de Pesquisa

\section{Método}

Para atingir o objetivo deste estudo, utilizou-se uma abordagem quantitativa. A pesquisa quantitativa possibilita identificar e medir a frequência e intensidade de comportamentos, atitudes e motivações de um determinado público alvo e que podem ser replicadas para o universo, entre outros fins (Hair, Money, Babin, \& Samouel, 2005).

Este estudo é de corte transversal, pois os dados serão coletados em um só ponto no tempo e sintetizados. Para os cálculos e validações dos testes estatísticos, desenvolvidos por meio da técnica de análise multivariada e modelagem por equações estruturais, utilizou-se o software Smart PLS 3.0.M3 (Ringle et al., 2015).

Para avaliar o tamanho da amostra e o poder estatístico das análises realizou-se uma análise com o software G*Power 3.1.5 (Faul, Erdfelder, Lang, \& Buchner, 2007; Faul, Erdfelder, Buchner, \& Lang, 2009). Considerando-se 2 preditores, nível de significância de $5 \%$, poder estatístico de o,8 e tamanho do efeito médio $\left(\mathrm{f}^{2}=0,15\right.$, que equivale a $\left.\mathrm{r}^{2}=13 \%\right)$, tem-se que o tamanho mínimo da amostra é de 68 respondentes. Para o desenvolvimento do 
instrumento de medida, foram adaptadas quatro escalas encontradas na literatura a fim medir os construtos envolvidos na estrutura do modelo.

Para a medida de intenção de permanecer nos projetos sociais, foi aplicada a Escala de Intenção Comportamentais (Ajzen, 1985), utilizando-se três indicadores que refletem a intenção comportamental ou desejo de permanecer nos projetos sociais.

Para medir as atitudes altruístas do indivíduo da amostra pesquisada, foi utilizada a Escala de Atitudes Altruístas (Loureiro \& Lima, 2009), composta por três construtos distintos. Já para medir o engajamento do indivíduo parte da amostra, será utilizada a Escala de Engajamento no Trabalho - EEGT (Siqueira et al., 2014). Para analisar a influência dos Custos de troca utilizou-se dois construtos da escala de Burnham et al. (2003).

\section{Coleta de Dados}

A coleta dos dados para esta pesquisa foi realizada com os alunos participantes dos projetos sociais de um grupo de instituições de ensino de nível superior que lançou programa social, que denominaremos de PROGRAMA X, uma vez que não é de interesse da organização ser identificada no estudo. O grupo contempla 110 faculdades em 10 estados e dois centros universitários. Por meio de um Fundo de Investimento próprio, as Faculdades Parceiras do grupo poderão efetuar o pagamento do Fundo de Financiamento Estudantil FIES - na fase de amortização - do aluno que optar em fazer o seu Curso e que esteja em situação de desemprego e/ou em dificuldades financeiras, ou que tenha optado em realizar um Curso de Licenciatura.e que desenvolvem atividades voluntárias e de contrapartida social, em ONGs cadastradas nas unidades do grupo. $\mathrm{O}$ universo de participantes cadastrados no PROGRAMA X atinge 3000 alunos.

Como instrumento de coleta de dados, utilizou-se um questionário estruturado. O questionário é composto por perguntas fechadas, em ordem pré-estabelecida caracterizando um survey.

Os questionários foram aplicados presencialmente e remotamente pela internet, durante 15 dias. A coleta presencial foi realizada em três instituições do grupo educacional que possuem esse projeto social, uma na região de São Caetano do Sul e duas na Mooca. 
Para a coleta pela internet, os questionários foram elaborados na plataforma do Google Docs.

A amostra do estudo foi composta por 351 respondentes, sendo que 280 questionários foram respondidos de forma presencial e 71 on-line.

\section{Análise dos Dados}

Analisando os dados obtidos em relação ao gênero, os resultados obtidos apontam que a amostra é caracterizada pela maioria do sexo feminino representando 228 respondentes, totalizando $64,9 \%$ dos respondentes do estudo.

Neste estudo verificou-se que a idade dos respondentes foi de 34,30 anos, sendo que a mediana foi de 33,0 anos.

Os dados mostram que $67,50 \%$ da amostra estavam empregados no momento da aplicação da pesquisa, o que corresponde a 237 pessoas. Quanto à renda dos participantes, 49,9\% dos respondentes pertencem a classe E, o que representa ter uma renda até dois salários mínimos.

Esta pesquisa procurou identificar como os respondentes tomaram conhecimento dos projetos sociais. Os resultados indicam que $48,4 \%$ dos respondentes obtiveram informações sobre a possibilidade de atuar nos projetos sociais da Instituição através dos amigos, pois os mesmos já estavam participando dos projetos sociais, $26,5 \%$ obtiveram essa informação na própria instituição.

\section{Avaliação do Modelo de Mensuração e Estrutural}

De acordo com o modelo teórico, três construtos são de segunda ordem: O construto Altruísmo é formado pelos construtos Afetivo (AAF), Cognição (ACOG) e Comportamental (ACOM).

O construto Custo de Troca é formado pelos construtos Benefício (CTBP) e Perdas Monetárias (CTPM). Já o construto Engajamento é formado pelos construtos Absorção (ENGA) e Vigor (ENGV). 
O modelo foi ajustado conforme as recomendações de Hair, Hult, Ringle, e Sarstedt (2014), por ter apresentado algumas cargas fatoriais inferiores a 0,7 , necessárias para gerar um mínimo de correlação entre os itens do construto. Depois de ter excluído alguns indicadores, as cargas fatoriais foram analisadas novamente, e são apresentadas na tabela 1.

Tabela 1

Cargas fatoriais cruzadas do modelo ajustado

\begin{tabular}{|c|c|c|c|c|c|c|c|c|c|c|}
\hline Variáveis & AAF & ACOM & $\begin{array}{c}\text { Altruís } \\
\text { mo }\end{array}$ & CTI & I & $\begin{array}{c}\text { Custo de } \\
\text { Troca }\end{array}$ & ENGA & 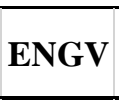 & $\begin{array}{c}\text { Engaja } \\
\text { mento }\end{array}$ & IP \\
\hline AAF1 & & 218 & $\mathbf{0 , 7 8 1}$ & 120 & 036 & $-0,064$ & 18 & 203 & 0,192 & 00 \\
\hline & & & & & 22 & & & & & \\
\hline AAF3 & & 08 & & 105 & 974 & $-0,036$ & 26 & 85 & 160 & \\
\hline AAF4 & & 0,336 & 0,739 & $-0,094$ & 078 & $-0,026$ & 84 & 223 & 1 & 082 \\
\hline ACOM1 & & & & & & & & & & \\
\hline ACOM4 & & & 0,615 & & & & & & & \\
\hline СТВP1 & 95 & o & $-0,132$ & & 18 & & & 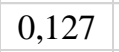 & 0 & 62 \\
\hline CTBP2 & & & & & 41 & & & & & 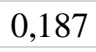 \\
\hline СТВР3 & 0,141 & & -0 , & 66 & 361 & 0,6 & 08 & 169 & 198 & 191 \\
\hline CTPM1 & ,086 & & 0,070 & & 815 & 0,677 & & 197 & & 139 \\
\hline СТPM2 & & & & & & & & & & \\
\hline EN & & & & & & & & 531 & 0 & \\
\hline ENGA2 & & & & & & 0 & & 638 & 0 & 24 \\
\hline ENGA3 & & & & & 18 & 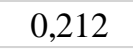 & & 781 & 4 & (3) \\
\hline ENC & & & 0 & 8 & 176 & 1 & & 55 & 50 & 461 \\
\hline ENGA5 & 154 & & & 0,085 & 0,132 & 0,118 & 617 & 477 & 70 & 0,210 \\
\hline ENGV1 & & & & & 4 & & 26 & 831 &, 753 & 65 \\
\hline & & & & & & & & & & \\
\hline & & & & & & & & & & \\
\hline ENGV & & & & & 125 & & 721 & $\mathbf{0 , 7 5 8}$ & 0,767 & 0,428 \\
\hline IP1 & & & & & 194 & 0,215 & 439 & 0,453 & 0,464 & 0,915 \\
\hline IP2 & 010 & 0,039 & 0,007 & 0,218 & 165 & 0,222 & 0,450 & 0,454 & 0,470 & $\mathbf{0 , 9 2 9}$ \\
\hline IP3 & 58 & 112 & 0,095 & 222 & 187 & 0,235 & 0,457 & 446 & 0,471 & 92 \\
\hline
\end{tabular}

Quase todos os indicadores apresentaram cargas fatoriais altas em suas variáveis latentes, superiores ou próximas a o,70 (validade convergente), e cargas fatoriais baixas nas demais variáveis latentes (validade discriminante), indicando razoável validade convergente e discriminante (Chin, 1998). Apesar de algumas variáveis continuarem um pouco abaixo de o,70, os indicadores de confiabilidade composta e Alfa de Cronbach dos construtos dessas variáveis apresentaram valores adequados, e optou-se por manter essas variáveis de acordo com as sugestões de Hair et al., (2014). 
Em relação ao construto de $2^{\underline{a}}$ ordem Altruísmo, ele manteve como preditores os construtos AAF e ACOM, porém, o construto ACOG não apresentou evidências de representar Altruísmo, sendo excluído do modelo. As demais variáveis latentes de $2^{\mathbf{a}}$ ordem (Custo de Troca e Engajamento) mantiveram-se conforme apresentadas no modelo teórico.

Os valores de AVE, Confiabilidade Composta e Alfa de Cronbach foram analisados novamente no modelo ajustado. A tabela 2 apresenta os indicadores mencionados.

Tabela 2

Modelo Ajustado: Variância Média Extraída, Confiabilidade Composta e Alfa de Cronbach

\begin{tabular}{llll}
\hline \multicolumn{1}{c}{ Construtos } & \multicolumn{1}{c}{ Variância Média } & Alfa de & \multicolumn{1}{c}{ Confiabilidade } \\
& Extraída (AVE) & Cronbach & Composta \\
\hline Afetivo & 0,665 & 0,831 & 0,888 \\
Comportamental & 0,668 & 0,507 & 0,801 \\
Altruísmo & 0,500 & 0,791 & 0,854 \\
Benefícios Perdidos & 0,621 & 0,695 & 0,831 \\
Perdas Monetárias & 0,664 & 0,494 & 0,798 \\
Custo de Troca & 0,500 & 0,748 & 0,833 \\
Absorção & 0,584 & 0,815 & 0,873 \\
Vigor & 0,654 & 0,822 & 0,883 \\
Engajamento & 0,568 & 0,902 & 0,921 \\
Intenção de Permanecer & 0,855 & 0,915 & 0,946 \\
\hline
\end{tabular}

Os valores estão dentro do estabelecido pelos autores, com a exceção do valor de consistência interna (Alfa de Cronbach) para os indicadores Comportamento, Perdas Monetárias e Benefícios Perdidos, que estão um pouco abaixo do recomendado. Porém, de acordo com Hair et al., (2014), o Alfa de Cronbach é sensível ao número de itens na escala e, geralmente, tende a subestimar a Consistência Interna, sendo mais apropriada a avaliação da Confiabilidade Composta, na qual os indicadores apresentaram valores adequados.

A tabela 3 apresenta a correlação ente as variáveis latentes, e a raiz quadrada da variância média extraída é apresentada em negrito na diagonal. Esse valor deve ser maior que a correlação entre as variáveis latentes (Fornell \& Larcker, 1981). 
Tabela 1

Validade Discriminante - Raiz Quadrada da AVE

\begin{tabular}{lcccc}
\hline & Altruísmo & $\begin{array}{l}\text { Custo de } \\
\text { Troca }\end{array}$ & Engajamento & $\begin{array}{c}\text { Intenção de } \\
\text { Permanecer }\end{array}$ \\
\hline Altruísmo & 0,707 & & & \\
Custo de Troca & $-0,071$ & 0,707 & & \\
Engajamento & 0,309 & 0,221 & 0,753 & \\
Intenção de Permanecer & 0,082 & 0,242 & 0,507 & 0,924 \\
\hline
\end{tabular}

Conforme verificado na tabela 3, no modelo ajustado, todos os valores da raiz quadrada da AVE estão adequados. A estatística t de Student analisa a hipótese de que os coeficientes de correlação são iguais a zero. Caso os resultados deste teste indiquem valores superiores a 1,96, evidencia-se que a correlação é significante (Efron \& Tibshirani, 1998; Hair et. al., 2014). A tabela 4 apresenta os coeficientes estruturais do modelo de medidos e estatística t de Student.

Tabela 4 Coeficientes estruturais do modelo de medidas e estatística t de Student

\begin{tabular}{|c|c|c|c|c|}
\hline Indicadores & Média & $\begin{array}{c}\text { Erro } \\
\text { padrão }\end{array}$ & Valor-t & P-valor \\
\hline AAF1 <- Altruísmo & 0,781 & 0,026 & 30,294 & 0,000 \\
\hline AAF2 <- Altruísmo & 0,812 & 0,026 & 30,893 & 0,000 \\
\hline AAF3 <- Altruísmo & 0,741 & 0,034 & 21,603 & 0,000 \\
\hline AAF4 <- Altruísmo & 0,740 & 0,033 & 22,368 & 0,000 \\
\hline ACOM1 <- Altruísmo & 0,504 & 0,056 & 9,006 & 0,000 \\
\hline ACOM4 <- Altruísmo & 0,616 & 0,050 & 12,301 & 0,000 \\
\hline CTBP1 <- Custo de Troca & 0,800 & 0,023 & 34,317 & 0,000 \\
\hline CTBP2 <- Custo de Troca & 0,692 & 0,038 & 18,159 & 0,000 \\
\hline CTBP3 <- Custo de Troca & 0,678 & 0,040 & 17,143 & 0,000 \\
\hline CTPM1 <- Custo de Troca & 0,677 & 0,034 & 19,925 & 0,000 \\
\hline CTPM2 <- Custo de Troca & 0,674 & 0,036 & 18,744 & 0,000 \\
\hline ENGA1 <- Engajamento & 0,620 & 0,040 & 15,697 & 0,000 \\
\hline ENGA2 <- Engajamento & 0,718 & 0,044 & 16,455 & 0,000 \\
\hline ENGA3 <- Engajamento & 0,874 & 0,014 & 64,244 & 0,000 \\
\hline ENGA4 <- Engajamento & 0,850 & 0,029 & 28,967 & 0,000 \\
\hline ENGA5 <- Engajamento & 0,569 & 0,062 & 9,218 & 0,000 \\
\hline ENGV1 <- Engajamento & 0,754 & 0,030 & 24,801 & 0,000 \\
\hline ENGV3 <- Engajamento & 0,737 & 0,037 & 19,835 & 0,000 \\
\hline ENGV4 <- Engajamento & 0,832 & 0,019 & 43,702 & 0,000 \\
\hline ENGV5 <- Engajamento & 0,766 & 0,028 & 27,440 & 0,000 \\
\hline IP1 <- Intenção de Permanecer & 0,914 & 0,014 & 67,591 & 0,000 \\
\hline IP2 <- Intenção de Permanecer & 0,929 & 0,010 & 88,821 & 0,000 \\
\hline IP3 <- Intenção de Permanecer & 0,928 & 0,011 & 85,615 & 0,000 \\
\hline & & & & \\
\hline
\end{tabular}


A próxima tabela apresenta os valores dos coeficientes entre os construtos e as respectivas estatísticas t de Student. Os valores também foram estimados pela técnica de bootstrapping. Todos os valores dos relacionamentos apresentaram valores de t de Student superiores a 1,96 (nível de significância $=5 \%$ ), com exceção do relacionamento entre Altruísmo e Intenção de Permanecer, que apresentou um valor de 1,024, não dando suporte para hipótese desse relacionamento.

Tabela 5

Coeficientes do modelo estrutural - entre construtos

\begin{tabular}{lllll}
\hline \multicolumn{1}{c}{ Indicadores } & Média & $\begin{array}{c}\text { Erro } \\
\text { padrão }\end{array}$ & Valor-t & P-valor \\
\hline Altruísmo -> Engajamento & 0,329 & 0,059 & 5,510 & 0,000 \\
Altruísmo -> Intenção de Permanecer & $-0,064$ & 0,061 & 1,024 & 0,306 \\
Custo de Troca -> Engajamento & 0,244 & 0,054 & 4,478 & 0,000 \\
Custo de Troca -> Intenção de Permanecer & 0,130 & 0,049 & 2,610 & 0,009 \\
Engajamento -> Intenção de Permanecer & 0,497 & 0,061 & 8,145 & 0,000 \\
\hline
\end{tabular}

Para avaliar o coeficiente de determinação $\left(\mathrm{r}^{2}\right)$, utilizou-se os estudos de Cohen (1988) e Faul et al. (2007), que determinam que valores iguais a 0,02, 0,15 e 0,35 são considerados, respectivamente, como pequenos, médios e grandes.

De acordo com as análises, o construto Engajamento apresentou um $\mathrm{r}^{2}$ de 0,154 , considerado médio, enquanto o construto Intenção de Permanecer apresentou um $\mathrm{r}^{2}$ de 0,278, considerado alto. Já os construtos de $2^{\underline{a}}$ ordem (Afetivo, Comportamento, Benefícios Perdidos, Vigor e Absorção), todos apresentaram $r^{2}$ acima de $25 \%$, com efeitos considerados altos.

A figura 2 apresenta o modelo resultante da pesquisa com os valores dos coeficientes entre os construtos com suas respectivas significâncias e os valores de poder de explicação, onde a linha tracejada representa relacionamentos que não foram evidenciados como estatisticamente significantes. 


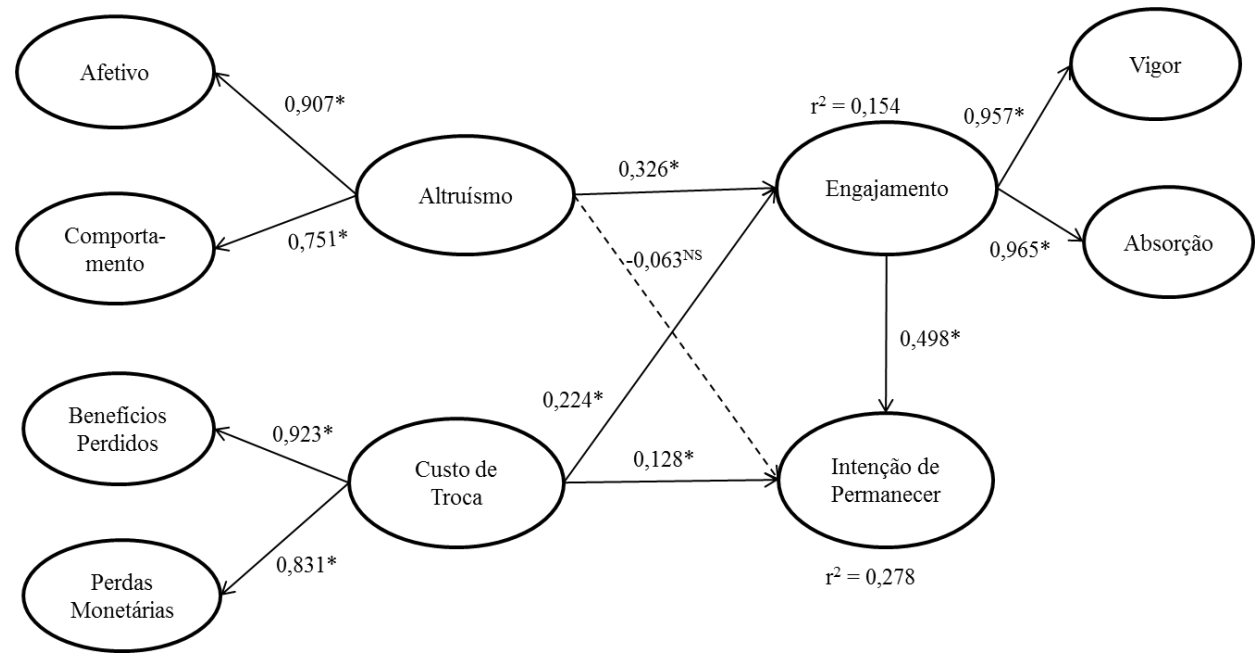

Figura 2. Modelo resultante da pesquisa

Notas: NS = não significante; * = significante a $5 \%$ )

\section{Discussão dos resultados}

A partir dos resultados, observa-se que a primeira hipótese - "O Altruísmo influencia positivamente no engajamento das pessoas no trabalho voluntário"- foi confirmada, corroborando com o estudo realizado por Knack (1992), onde o autor obteve bons resultados com seu índice de altruísmo e com as questões relacionadas ao engajamento no trabalho voluntário.

A segunda hipótese não foi confirmada, portanto de acordo com os resultados deste estudo, não se pode afirmar que o Altruísmo influencia positivamente na intenção de permanecer nos projetos sociais. A constatação de que participar dos projetos sociais significa ter a amortização de sua dívida como prêmio não condiz com atitudes verdadeiramente altruístas. Portanto, este estudo corrobora com estudos de $\mathrm{Hu}$ e Liu (2003) onde o altruísmo é comumente visto como um ato em que uma pessoa disponibiliza bens ou serviços a uma outra sem solicitar uma forma de compensação.

Foi confirmada a terceira hipótese, onde constatou-se que o engajamento das pessoas na organização influencia positivamente na intenção de permanecer nos projetos sociais. Pessoas engajadas tendem a executar suas atribuições com mais vigor e dedicação e, consequentemente, podem permanecer atuantes nas organizações (Cavalcante et al., 2015). 
A quarta hipótese foi confirmada, onde constatou-se que os Custos de troca influenciam positivamente no engajamento dos alunos nos projetos sociais corroborando com estudos que indicam que as pessoas engajadas podem estar motivadas extrinsecamente, agindo, por exemplo, em função de alguma recompensa, ou para evitar punições e perdas (Harris, 2011; Reeve et al., 2004).

A quinta hipótese deste estudo também foi confirmada, onde foi identificado que os Custos de troca influenciam positivamente na intenção de permanecer nos projetos sociais, corroborando com estudos de Jones et al. (2007) que diz que tanto a perda de benefícios quanto as mudanças sociais refletem valores e comportamentos positivos que podem ser sacrificados no processo de mudança, e essas perdas influenciam na permanência do indivíduo nos projetos sociais. No quadro 1, sintetizam-se os resultados das hipóteses levantadas neste estudo.

\begin{tabular}{|c|c|c|}
\hline Hipóteses & Descrição & Resultado \\
\hline $\mathrm{H}_{1}$ & $\begin{array}{l}\text { O Altruísmo influencia positivamente no engajamento das } \\
\text { pessoas no trabalho voluntário }\end{array}$ & CONFIRMADA \\
\hline $\mathrm{H}_{2}$ & $\begin{array}{l}\text { O Altruísmo influencia positivamente na intenção de } \\
\text { permanecer nos projetos sociais. }\end{array}$ & NÃO CONFIRMADA \\
\hline $\mathrm{H}_{3}$ & $\begin{array}{l}\text { O engajamento das pessoas na organização influencia } \\
\text { positivamente na intenção de permanecer nos projetos } \\
\text { sociais. }\end{array}$ & CONFIRMADA \\
\hline $\mathrm{H}_{4}$ & $\begin{array}{l}\text { Os Custos de troca influenciam positivamente no } \\
\text { engajamento dos alunos nos projetos sociais. }\end{array}$ & CONFIRMADA \\
\hline $\mathrm{H}_{5}$ & $\begin{array}{l}\text { Os Custos de troca influenciam positivamente na intenção } \\
\text { de permanecer nos projetos sociais. }\end{array}$ & CONFIRMADA \\
\hline
\end{tabular}

Quadro 1. Síntese dos testes de hipóteses do estudo

Neste estudo foi feita uma relação dos construtos de segunda ordem de todas as escalas utilizadas. No caso do altruísmo, o construto Cognição não apresentou evidências de estar associado ao Altruísmo, sendo excluído do modelo. A dimensão cognitiva inclui as percepções e conhecimento do objeto (Donat et al., 2009. pg. 39) e essa pode ser uma das prováveis causas da falta de evidências que associem o construto ao altruísmo, pelo fato de que os participantes dos projetos sociais analisados neste estudo não conheciam os projetos antecipadamente, somente $11,40 \%$ já estavam atuando em trabalho voluntário. 
$\mathrm{Na}$ análise sobre o engajamento e a intenção de permanecer em projetos sociais, considerou-se como fatores preditores o altruísmo, os custos de troca e o engajamento. Se, por um lado, razões altruístas foram identificadas como importantes fatores motivadores para o trabalho voluntário, como consta na pesquisa de Farrel, Johnston, \& Twynam., (1998), os resultados deste estudo confirmam que o altruísmo é um preditor do engajamento nos trabalhos voluntários, mas sua relação com a intenção em permanecer nos projetos sociais, onde é desenvolvido o trabalho voluntário, não foi confirmada.

Assim como Burnham et al. (2003) encontraram relação entre os custos de troca e a intenção comportamental de recompra, este estudo confirmou que os custos de troca implicam no engajamento e na intenção de permanecer nos projetos sociais. Os custos de benefícios e os custos de perdas monetárias envolvem a perda financeira e muitas vezes não estão expressos de forma mensurável, mas são percebidos pelo cliente, quando este se depara com o processo de troca (Burnham et al., 2003).

Em relação à intenção de permanecer nos projetos sociais, conclui-se, pela existência de resultados confirmados neste trabalho, que as dimensões do engajamento estão relacionadas à intenção de permanecer. Estudos realizados indicam que o engajamento deve abranger um comprometimento e alinhamento através de um propósito, visão e interesses comum (Bakker \& Demerouti, 2011).

\section{Implicações Para a Teoria}

Sob a perspectiva acadêmica, este trabalho, além de reaplicar as escalas já validadas e introduzir o tema projetos sociais e contrapartida social, agrega ao corpo do conhecimento da área a relação entre custos e altruísmo. A primeira contribuição refere-se à reaplicação do modelo de Burnham et al. (2003), que desenvolveu uma investigação identificando os tipos custo de mudança, ou custo de troca. Neste estudo comprova-se, através dos resultados, que os custos de troca infuenciam nas intenções dos voluntários em permanecer nos projetos sociais como também influenciam o engajamento no trabalho voluntário desenvolvido nos projetos sociais.

Esta pesquisa colabora para a compreensão que não apenas construtos amplamente estudados, como satisfação, confiança, comprometimento, entre outros, impactam no 
engajamento e na intenção em permanecer na organização, mas que também os custos de troca e o altruísmo têm influência no engajamento e na permanência dos indivíduos em projetos sociais.

O estudo atende a chamada de Loureiro \& Lima (2009) sobre ampliar os estudos da escala de atitudes altruístas de forma a continuar a análise da validade e a melhorar a fiabilidade. Esses autores sugerem que isto deverá ser feito mediante um aumento e diversificação da amostra. Neste trabalho aumentou-se o número de participantes da amostra de 213 para 351 e a diversificação ocorreu pelo fato de serem participantes de unidades e locais diferentes.

A utilização de outros construtos que possam ampliar o entendimento do engajamento e a aplicação de valores humanos também foi sugerida por Coelho (2014). Este estudo corroborou com a requisição do autor ao ampliar o estudo relacionando engajamento com altruísmo e custos de troca e também com a intenção de permanecer em projetos sociais.

\section{Implicações Para a Prática}

Ações gerenciais podem ser elaboradas através dos resultados observados sobre impacto do altruísmo no engajamento. Dentre as diferentes formas de se engajar pessoas, as ações altruístas podem representar uma nova estratégia para as organizações. Estratégias podem ser utilizadas para aumentar a satisfação e a fidelização dos profissionais ou voluntários no trabalho. São elas: mapear questões relacionadas às características altruístas dos empregados e criar estratégias para garantir a melhoria das condições de trabalho que sejam compatíveis com essas características. As ações de responsabilidade social desenvolvidas pela empresa podem ser uma dessas estratégias.

Como contribuição prática para as empresas envolvidas nesta pesquisa, os dados obtidos poderão servir para elucidar questões relacionadas ao comportamento dos envolvidos em projetos sociais e os fatores motivadores de sua permanência, possibilitando, assim, um melhor planejamento de suas políticas com relação à retenção de pessoas e as estratégias de engajamento nos projetos sociais desenvolvidos por essas instituições. 
O ser humano é movido por desejos básicos de ser aceito, compreendido, apreciado e reconhecido (Vergara, 2000). A recompensa financeira, a oportunidade de crescimento e o bom relacionamento com colegas de trabalho são fundamentais para manter a motivação do colaborador, facilitando o engajamento. Nesse sentido, a compreensão de motivações e determinantes do comprometimento com o trabalho voluntário torna-se crucial para que os gestores desta força de trabalho possam desenhar mecanismos eficazes de atração, engajamento e retenção, a fim de que os objetivos organizacionais e de seus colaboradores sejam atendidos.

Os resultados desta pesquisa ainda podem contribuir de forma com que a instituição e seus gestores, possam estar munidos de informações acerca dos fatores que incentivam a permanência nos projetos sociais, para que assim possam melhor se planejar, direcionar e tomar medidas necessárias em torno desta ferramenta como, por exemplo, incentivando a cidadania e executando a sua responsabilidade social, que ocorre quando empresas, de forma voluntária, adotam posturas, comportamentos e ações que promovam o bem-estar dos seus públicos interno e externo (Camargo, 2010).

\section{Conclusões}

O estudo realizado teve como objetivo analisar se altruísmo e custos de troca são preditores do engajamento e da intenção de permanecer em projetos sociais e se o engajamento também influencia positivamente na intenção de permanecer em projetos sociais.

Os resultados deste estudo indicam que o engajamento no trabalho afeta consideravelmente a intenção de permanecer em projetos sociais. Isto significa que o indivíduo que apresenta vigor e absorção também tem a intenção comportamental de permanecer inseridos nos projetos sociais. Evidenciou-se, também, que o altruísmo impactou muito mais no engajamento do que os custos de troca. O resultado comprova que os vínculos afetivos desenvolvidos nos trabalhos voluntários são mais significativos do que os prováveis custos que podem ocorrer mediante uma desistência de se atuar nos projetos sociais. 
Pode-se considerar como atingidos os objetivos do presente trabalho de investigar os antecedentes do engajamento no trabalho e da intenção de permanecer nos projetos sociais, na medida em que quatro das cinco hipóteses foram confirmadas.

\section{Limitações da pesquisa}

Dentre as limitações deste estudo podem ser citados o contexto utilizado na pesquisa, ou seja, participantes de um projeto específico e a limitação de escolhas teóricas. A utilização de um único contexto pode interferir na validade externa dos achados (Basso, 2012). A utilização de um único contexto propicia maior solidez aos resultados. Entretanto, sugere-se que outros estudos empreguem contextos distintos a fim de verificar se o comportamento altruísta pode ser identificado em situações diferentes, não apenas em ONGs (Basso, 2012).

Em relação às escolhas teóricas feitas, o estudo é limitado pela ausência de temas como lealdade e comprometimento, que poderiam ampliar os resultados do estudo, servindo como sugestão para estudos futuros.

\section{Sugestões para estudos futuros}

Sugere-se que novos estudos verifiquem a possibilidade de identificar o comportamento altruísta em outros setores das organizações, sem a relação com trabalhos voluntários, para verificar sua influência com o engajamento no trabalho. Dessa forma, seria possível identificar estratégias efetivas para o comprometimento com a organização, uma vez que, este estudo corroborou com a identificação do comportamento altruísta influenciando o engajamento no trabalho.

Outra sugestão de estudos futuros diz respeito à utilização de formas de recompensa, complementando os custos e a avaliação dos efeitos sobre os indicadores de engajamento.

Por fim, considerando que o estudo foi feito com um grupo de indivíduos, participantes de projetos sociais, acredita-se que uma amostra com respondentes em outros Estados poderiam implicar conclusões com maior potencial de generalização. 


\section{Referências}

Ajzen, I. (1985). From intentions to actions: A theory of planned behavior. In J. Kuhl, J. Beckmann (Eds.). Action control: From Cognition to Behavior. (11-39). Springer Berlin Heidelberg.

Alves, D. A., Terres, M. S., \& Santos, C. P. (2013). Custos de mudança e seus efeitos no comprometimento, na intenção de recompra e no boca-a-boca em serviços educacionais. Base, 10(4).

Bakker, A. B., Albrecht, S. L., \& Leiter, M. P. (2011). Key questions regarding work engagement. European Journal of Work and Organizational Psychology, 20(1), 4-28.

Bakker, A. B., \& Demerouti, E. (2008). Towards a model of work engagement. Career development international, 13(3), 209-223.

Bakker, A. B., \& Leiter, M. P. (Eds.). (2010). Work engagement: A handbook of essential theory and research. Psychology Press.

Basso, K. (2012). Violação e recuperação da confiança do cliente após o duplo desvio. (Tese Doutorado, Universidade Federal do Rio Grande do Sul). Recuperado de http://www.lume.ufrgs.br/handle/10183/62120

Burnham, T. A., Frels, J. K., \& Mahajan, V. (2003). Consumer switching costs: a typology, antecedents, and consequences. Journal of the Academy of marketing Science, 31(2), 109126.

Camargo, J. M. P. As vantagens competitivas da responsabilidade social empresarial. In Âmbito Jurídico - Comercial, Rio Grande, XIII, n. 78, jul 2010. Recuperado de http://www.ambitojuridico.com.br/site/index.php?n_link=revista_artigos_leitura\&artig o_id=7992

Carvalho, F. M., \& Barbalho, L. (2006). Docência e exaustão emocional. Educ. Soc, 27(94), 229-253. 
Cavalcante, M. M., Siqueira, M. M. M., \& Kuniyoshi, M. S. (2015) Engajamento, Bem estar no trabalho e Capital Psicológico: Um estudo com profissionais da área de Gestão de pessoas. Pensamento \& Realidade. Revista do Programa de Estudos Pós-Graduados em Administração-FEA, 29(4), 23.

Chin, W. W. (1998). The partial least squares approach to structural equation modeling. Modern methods for business research, 295(2), 295-336.

Coelho, G. L. D. H. (2014). Valores humanos nas organizações: relação com a síndrome de Burnout e o engajamento laboral. (Dissertação de Mestrado, Universidade Federal da Paraíba). Recuperado de http://tede.biblioteca.ufpb.br/handle/tede/6984\#preview-linko

Cohen, J. (1988). Statistical power analysis for the behavioral sciences. (2. ed.). Hillsdale, NJ: Erlbaum.

Comte, A.(1934) Catecismo positivista. Rio de Janeiro: Apostolado Positivista do Brasil.

Domeneghetti, A. M. (2001). Voluntariado-gestao do trabalho. Editora Esfera.

Donat, E., Brandtweiner, R., \& Kerschbaum, J. (2009). Attitudes and the digital divide: Attitude measurement as instrument to predict internet usage. Informing Science: the International Journal of an Emerging Transdiscipline, 12(1), 37-56.

Drucker, P. F. (1997). A organização do futuro: como preparar hoje as empresas de amanhã. São Paulo: Futura.

Efron, B., \& Tibshirani, R. J. (1993). An introduction to the bootstrap. New York:.Chapman \& Hall.

Elster, J. (1989). Nuts and Bolts for the Social Sciences. Cambridge: Cambridge University Press.

FarrelL, J. M., Johnston M. E., \& Twynam G. D.(1998) Volunteer motivation, satisfaction, and management at an elite sporting competition. Journal of Sport Management, 12(4). 
Faul, F., Erdfelder, E., Buchner, A., \& Lang, A. G. (2009). Statistical power analyses using G* Power 3.1: Tests for correlation and regression analyses. Behavior research methods, 41(4), 1149-116o.

Faul, F., Erdfelder, E., Lang, A. G., \& Buchner, A. (2007). G* Power 3: A flexible statistical power analysis program for the social, behavioral, and biomedical sciences. Behavior research methods, 39(2), 175-191.

Fornell, C., \& Larcker, D. F. (1981). Evaluating structural equation models with unobservable variables and measurement error. Journal of marketing research, 39-50.

Friedman, R. L., Manly, S. P., McMahon, M., Kerr, I. M., \& Stark, G. R. (1984). Transcriptional and posttranscriptional regulation of interferon-induced gene expression in human cells. Cell, 38(3), 745-755.

Gómez, J., \& Maícas, J. P. (2011). Do switching costs mediate the relationship between entry timing and performance? Strategic Management Journal, 32(12), 1251-1269.

Grzybowski, L. (2008). Estimating switching costs in mobile telephony in the UK. Journal of Industry, Competition and Trade, 8(2), 113-132.

Hair Jr, J. F., Hult, G. T. M., Ringle, C., \& Sarstedt, M. (2014). A primer on partial least squares structural equation modeling (PLS-SEM). Sage Publications.

Hair Jr, J. F., Money, A. H., Babin, B., \& Samouel, P. (2005). Fundamentos de métodos de pesquisa em administração. Porto Alegre: Bookman.

Harris, L. (2011). Secondary teachers' conceptions of student engagement: Engagement in learning or in schooling?. Teaching and Teacher Education, 27(2), 376-386.

Houaiss, A., Villar M. S., \& Franco F. M. M.(2009). Dicionário Houaiss da língua portuguesa. Rio de Janeiro: Objetiva.

Hu, Y. A., \& Liu, D.Y. (2003). Altruism versus egoism in human behavior of mixed motives. American Journal of Economics and Sociology, 62(4), 677-705. 
Jones, M. A., Reynolds, K. E., Mothersbaugh, D. L., \& Beatty, S. E. (2007). The positive and negative effects of switching costs on relational outcomes. Journal of Service Research, 9(4), 335-355.

Kahn, W. A. (1990). Psychological conditions of personal engagement and disengagement at work. Academy of management journal, 33(4), 692-724.

Klemperer, P. (1995). Competition when consumers have switching costs: An overview with applications to industrial organization, macroeconomics, and international trade. The review of economic studies, 62(4), 515-539.

Knack, S. (1992). Social Altruism and Voter Turnout: Evidence from the 1991 NES Pilot Study. 1991. NES Pilot Study Reports, 1992.

Lacerda Neto, A. V. (2015). O manifesto do altruísmo. Iusgentium, 11(6), 202-207.

Lam, S. Y., Shankar, V., Erramilli, M. K., \& Murthy, B. (2004). Customer value, satisfaction, loyalty, and switching costs: an illustration from a business-to-business service context. Journal of the academy of marketing science, 32(3), 293-311.

Leeds, R. (1963). Altruism and the norm of giving. Merrill-Palmer Quarterly of Behavior and Development, 9(3), 229-240.

Leiter, M. P., \& Maslach, C. (1997). The truth about burnout: How Organizations Cause Personal Stress and What to do About it Paperback. Jossey-Bass.

Loureiro, A., \& Lima, M. L. (2009). Escala de atitudes altruístas: Estudo de validação e fiabilidade. Laboratório de Psicologia, 7, 73-83.

Mascarenhas, A. O., Zambaldi, F., \& Varela, C. A. (2013). Motivação em Programas de Voluntariado Empresarial: Um Estudo de Caso. Organizações em Contexto, 9(17), 229246.

Maslach, C., Schaufeli, W. B., \& Leiter, M. P. (2001). Job burnout. Annual review of psychology, 52(1), 397-422. 
Morgan, R. M., \& Hunt, S. D. (1994). The commitment-trust theory of relationship marketing. The journal of marketing, 20-38.

Moura, L. R. C., Veiga, R. T., Cunha, N. R. S., \& Moura, L. (2010). Um estudo comparativo de três teorias concorrentes da ação para explicar o comportamento da tentativa de perder peso. In XXXIV Encontro da Anpad. São Paulo.

Pearce, D. (1998). Cost benefit analysis and environmental policy. Oxford review of economic policy, 14(4), 84-100.

Pedagógico, P. Universitário Capital IGA-№ 1. Manual dos Projetos Sociais (2015).

Penner, L. A. (2002). Dispositional and organizational influences on sustained volunteerism: An interactionist perspective. Journal of Social Issues, 58(3), 447-467.

Porter, M. E. (1992). Vantagem competitiva: criando e sustentando um desempenho superior (Vol. 511, pp. 1989-13). Rio de Janeiro: Campus.

Porter, M. E., \& Kramer, M. R. (2002). The competitive advantage of corporate philanthropy. Harvard Business review, 8o(12), 56-68.

Reeve, J., Deci, E. L., \& Ryan, R. M. (2004). Self-determination theory. A dialectical framework for understand sociocultural influences on student motivation. In D. M. McInerney \& S. Van Etten (Eds.). Big Theories Revisited (p.31-58). Connecticut: Age Publishing.

Ringle, C. M., Wende S., \& Becker J. (2015). SmartPLS 3. Bönningstedt: SmartPLS.

Rivera, A. N. (1980). Factores que determinan la atribución de altruismo. Revista Latinoamericana de Psicología, 12(1), 63-77.

Rose-Ackerman, S. (1997). The political economy of corruption. Corruption and the global economy, 31, 60. 
Rosenberg, M. J., \& Hovland, C. I. (1960). Cognitive, affective, and behavioral components of attitudes. Attitude organization and change: An analysis of consistency among attitude components, 3, 1-14.

Salanova, M., Salanova, W., Schaufeli, W. B., Salanova, M., Salanova, S., \& Llorens, S. (2009). El engagement en el trabajo: cuando el trabajo se convierte en pasión (No. 65.013). Alianza.

Sarti, D. (2014). Job resources as antecedents of engagement at work: evidence from a longterm care setting. Human Resource Development Quarterly, 25(2), 213-237.

Siqueira, M. M. M., Martins, M. C. F., Orengo, V., \& Souza, W. S. (2014). Engajamento no Trabalho. In M. M. M. Siqueira, (Org.). Novas Medidas do Comportamento Organizacional. Porto Alegre, Artmed.

Smith, D. (1982). Altruism, volunteers and volunteerism. In J. Harmon (Org.). Volunteerism in the eighties: fundamentals issues in voluntary action. Washington D.C.: University Press of America.

Sturmer, S., Snyder, M., \& Omoto, A. M. (2005). Prosocial emotions and helping: the moderating role of group membership. Journal of personality and social psychology, $88(3)$

Thomas, W. I., \& Znaniecki, F. (1918). The Polish peasant in Europe and America: Monograph of an immigrant group (Vol. 2). University of Chicago Press. 